\title{
Oral Hygiene Facilitators and Barriers in Greek 10 Years Old Schoolchildren
}

\author{
${ }^{1}$ Matina Angelopoulou, ${ }^{2}$ Katerina Kavvadia, ${ }^{3}$ Constantine Oulis, ${ }^{4}$ Christina Reppa
}

\section{ABSTRACT}

Aim: The aim of this study was to determine the oral hygiene facilitators and barriers for 10 years old Greek children, via a questionnaire and clinical examination.

Materials and methods: This was a cross-sectional study of 266, 10 years old, children recruited from schools in 3 locations in Greece. Data were collected via questionnaires and clinical examination. Questionnaires referred to children's oral hygiene knowledge, behavior and attitude as well as parents' oral hygiene behavior and educational level. Children were clinically examined by two calibrated pediatric dentists using a WHO probe and artificial light to assess dental plaque (hygiene index-HI), gingivitis (simplified gingival index-GIs) and dental caries (DMFT-BASCD criteria).

Results: Regarding oral hygiene knowledge, although $80 \%$ of the children were literate of the proper means of oral hygiene, only $58.64 \%$ brushed their teeth twice daily and $36.84 \%$ used dental floss. Children's oral hygiene knowledge was positively correlated with both parental brushing frequency $(\rho=0.175$, $p<0.05)$ and educational level $(\rho=-0.216, p<0.05)$. Toothpaste use was reported by $92.11 \%$ of the children. Regarding children's attitude, $62.28 \%$ were concerned whether their teeth were clean, with girls showing greater concern than boys $(p<0.001)$. Their reported beliefs regarding brushing avoidance were boredom $(84.06 \%)$, low oral health literacy $(73.91 \%)$ and forgetfulness (56.52\%).

Conclusion: Oral hygiene facilitators were found to be the concern about how clean were their teeth, oral health literacy of both children and parents and toothpaste appeal to children. Oral hygiene barriers were children's boredom, low oral health literacy, forgetfulness and low socioeconomic level.

Keywords: Barriers, Facilitators, Motivation, Oral hygiene, Schoolchildren, Toothbrushing.

How to cite this article: Angelopoulou M, Kavvadia K, Oulis C, Reppa C. Oral Hygiene Facilitators and Barriers in Greek 10 Years Old Schoolchildren. Int J Clin Pediatr Dent 2015;8(2): 87-93.

\footnotetext{
${ }^{1}$ Assistant Professor, ${ }^{2}$ Associate Professor, ${ }^{3}$ Professor ${ }^{4}$ Postgraduate Student

${ }^{1}$ Department of Developmental Sciences, Marquette University School of Dentistry, WI, United States

${ }^{2-4}$ Department of Pediatric Dentistry, Dental School, University of Athens, Attica, Greece
}

Corresponding Author: Matina Angelopoulou, Assistant Professor, Department of Developmental Sciences, Marquette University, School of Dentistry, WI, United States, Phone: 4142886790, e-mail: matinangelop@yahoo.gr
Source of support: Colgate, Greece

Conflict of interest: None

\section{INTRODUCTION}

Oral hygiene is the most effective measure to prevent caries and periodontal disease. ${ }^{1,2}$ Ideally brushing should be performed twice a day in order to maintain oral health. ${ }^{1}$ However, many children globally brush less than once a day. ${ }^{3-5}$ More specifically in Greece, results of a recent epidemiological survey showed that $68.7 \%$ of 12 years old children brush occasionally, $78,2 \%$ had average or poor oral hygiene while $41.5 \%$ had gingivitis. ${ }^{6}$ The above findings show a necessity to define the facilitators and barriers of oral hygiene in order to motivate children and improve their oral health.

Motives for oral hygiene have been examined in the past in adolescents. ${ }^{7,8}$ Results of these studies suggest that concerns of teeth cleanliness, attraction to the opposite gender, self-esteem and family structure can facilitate or impede the performance of oral hygiene in adolescents. ${ }^{7,8}$ The influence of socioeconomic factors on oral hygiene practices among primary schoolchildren have been extensively studied. ${ }^{5,9-12}$ Facilitators of oral hygiene in primary schoolchildren found previously were high self-esteem, peers influence and personal appearance. ${ }^{13-16}$ However, clinical oral health status of children has not reported in any of the previous studies regardless the fact that is a more objective method to evaluate oral health rather than questionnaires or interviews. Also, the target group in these studies was greater than 10 years old and no data exist in younger children. Moreover, most studies focus on specific factors influencing the oral hygiene and do not investigate the variety of facilitators and barriers in primary schoolchildren.

The aim of this study was to determine facilitators and barriers of oral hygiene in 10 years old Greek schoolchildren in relation to socioeconomic data, children's oral hygiene knowledge, behavior, attitude and clinical oral status.

\section{MATERIALS AND METHODS}

\section{Study Design}

This was a cross-sectional study of facilitators and barriers of oral hygiene in primary schoolchildren in relation to 
socioeconomic data, children's oral hygiene knowledge, behavior, and attitude and clinical oral status. After parental informed consent oral hygiene knowledge, behavior and attitude of children and their parents were evaluated via questionnaire while clinical parameters were evaluated through clinical examination. This study has been conducted in full accordance with the World Medical Association Declaration of Helsinki and was approved by the Athens University Ethical Committee and the Greek Ministry of Education (30.10.09, No126516/ Г7).

\section{Outcome Measures}

The primary outcome was to evaluate the level of oral hygiene, knowledge, behavior, attitude, clinical oral status and socioeconomic level in order to determine the facilitators and barriers of oral hygiene.

\section{Sample}

Inclusion criteria for sample recruitment was based on: (a) the age to be attending the 4th grade of primary school (9 to 10 years old), (b) the type of population to be of rural, low urban or high urban locations, as determined by the Hellenic Statistical Authority, (c) the schools to be from the ones participated in the national oral health education program and (d) the children not to have contributory medical history.

The sample recruited, consisted of 266, 10 years old students from seven public primary schools around Greece.

\section{Questionnaires}

After parental informed consent, data regarding children's oral hygiene knowledge, attitude and behavior were collected via a questionnaire, completed at the school. The questionnaire had multiple choice questions on knowledge of toothbrushing, dental flossing, oral health behavior, parental involvement in oral hygiene and children's feelings about oral cleanliness and barriers that lead to brushing avoidance. A different questionnaire was send to the parents regarding their educational level and brushing frequency. Both questionnaires were distributed to 20 persons prior to their application for validation.

\section{Clinical Examination}

All children were clinically examined in their classroom by two calibrated pediatric dentists, under all infection control measures, using a mirror, a periodontal probe (WHO-621) and artificial light. The following variables were recorded: (a) dental plaque by a modification of hygiene index (HI) of Lindhe, without the use of a disclosing agent 18, (b) gingivitis as presence or absence of gingival bleeding upon periodontal probing (WHO periodontal probe) by the simplified gingival index (GI-S) ${ }^{17}$ and (c) dental caries (DMFT), according to the diagnostic criteria of the British Association of Community Dentistry, BASCD. ${ }^{18}$

\section{Statistical Analysis}

Power analysis was performed with $\mathrm{G}^{*}$ Power software and was $86 \%$ at $\alpha=0.05$.

Data were reported descriptively by calculating Frequency, Mean and Standard Deviation (SD). For caries index, inter examiner reliability was assessed using the intraclass correlation coefficient (ICC) in 20 patients.

Spearman's correlation coefficient was used to investigate any correlation between the various parameters from the questionnaire and clinical examination. MannWhitney U-test/Kruskal-Wallis test were used for statistical comparison between demographic data and data from the questionnaires and clinical examination. Nonparametric tests were used since data did not have a normal distribution. Statistical significant differences were investigated at the level of $\mathrm{p}<0.05$ using SPSS software (IBM SPSS Statistics 20.0 Armonk, NY).

\section{RESULTS}

Sample demographic data and level of parental education are presented in Table 1.

\section{Oral Hygiene Knowledge}

Regarding brushing frequency, $82.71 \%$ of children knew that they should brush their teeth at least twice a day. Children with knowledge of appropriate brushing frequency brushed more frequently $(\rho=0.288, p<0.001)$, had lower Hygiene Index $(\rho=0.186, p<0.05)$, were most often girls $(\rho=0.185, p<0.05)$ and their parents brushed as well more frequently $(\rho=0.175, p<0.05)$. Correlation between the variables are presented in Table 2 .

Regarding dental floss's use, $77.44 \%$ knew that it is used to clean the interproximal surfaces of teeth. Children with knowledge of appropriate use of the dental floss used it more frequently $(\rho=0.260, p<0.001)$ and their parents had higher educational level $(\mathrm{p}<0.05)$.

\section{Oral hygiene Behavior}

Regarding brushing frequency, as presented in the pie chart in Graph 1, 58.64\% reported that they brush their teeth at least twice a day. Toothpaste use was reported by $92.11 \%$ of the children and flossing by $36.84 \%$. 


\begin{tabular}{lll}
\hline \multicolumn{2}{l}{ Table 1: Demographic data of the sample } \\
\hline & & $N$ \\
\hline Children & Gender & 142 \\
& Male & 124 \\
& Female & \\
& Type of population & 89 \\
& Low urban & 98 \\
& Rural & 79 \\
& High urban & \\
Father's educational level & 50 \\
& Low & 86 \\
& Moderate & 122 \\
& Higher & 8 \\
& Unknown & \\
Mother's educational level & 46 \\
Low & 74 \\
Moderate & 138 \\
Higher & 8 \\
Unknown & 266 \\
\hline Total & 1
\end{tabular}

Those children that had their parents involved during brushing, used flossing more often $(\rho=0.349, p<0.001)$. Also, lower dmft score was associated with higher flossing frequency $(\mathrm{p}<0.05)$.

\section{Oral Hygiene Attitude}

Concerning their attitude, $61.28 \%$ were very concerned about how clean were their teeth with girls being significantly more concerned than boys $(\mathrm{p}<0.001)$.

Brushing avoidance for this age group and children's own beliefs' are presented in the histogram of Graph 2.

\section{Oral Status}

Regarding the sample's clinical parameters, DMFT was $0.65(\mathrm{SD}=1.15)$, dmft was $1.74(\mathrm{SD}=2.53)$, hygiene index was $57.40 \%(\mathrm{SD}=29.26)$ and Gingival Index was 33.60\% $(\mathrm{SD}=20.64)$. Inter examiners reliability for $\mathrm{dmft} / \mathrm{DMFT}$

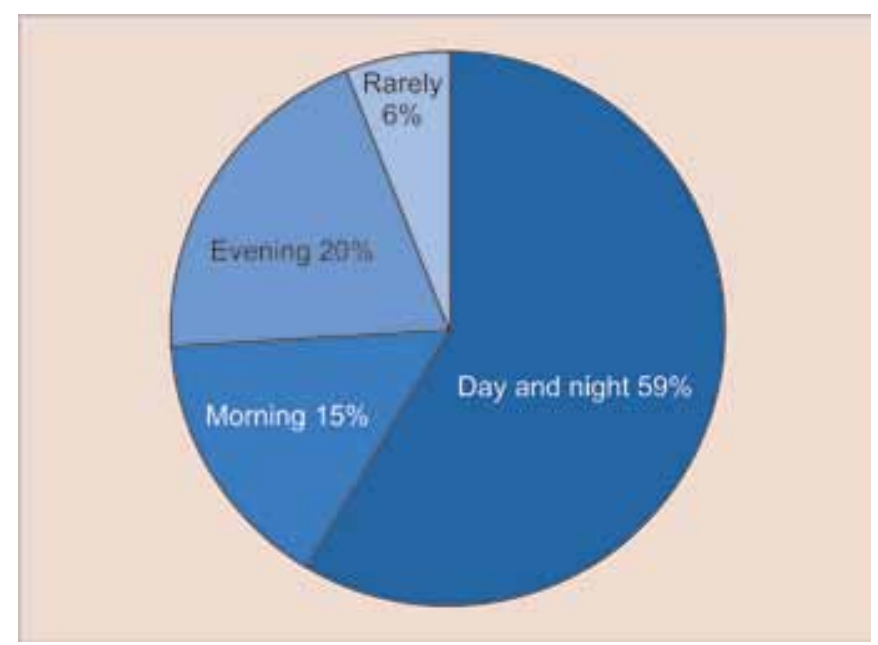

Graph 1: Brushing frequency in 10 years old children index was ICC $=0.89$. Caries index of primary dentition $(\mathrm{dmft})$ was correlated with parental educational level ( $\rho=-0.305, p<0.001)$, the lower the educational level the higher the dmft index $(\mathrm{p}<0.001)$. Children with higher hygiene index had significantly lower caries $(\rho=-0.166$, $p<0.05)$ and less gingivitis $(\rho=-0.608, p<0.001)$.

\section{DISCUSSION}

Results of the present study suggest that facilitators for oral hygiene in 10-year-old Greek schoolchildren are children's and parents' oral health education, the appeal to the toothpaste and the concern for oral cleanliness (Table 3). Barriers are the low socioeconomic level, boredom, poor oral hygiene literacy and forgetfulness (Table 3).

The sample of the present study was selected from participating schools in the Greek national oral health education program. ${ }^{19}$ The sample was chosen so as to include schools from rural and urban areas of low and high socioeconomic levels.

The specific age group was selected because children at that age can express their own beliefs without the need of parental involvement. Also, children at this age are capable of expressing their opinion more accurately than when their parents answer on their behalf. ${ }^{20}$ Moreover, a recent epidemiological study in Greece showed that 12 years old children had high prevalence of gingivitis. ${ }^{6}$ This finding suggested that oral health education should be implemented at an earlier age in order to improve plaque removal and control gingivitis, later in adolescence. As reported oral health habits formed in early years can lead to healthy habits during adolescence and adulthood..$^{13,21}$

The oral status was assessed through quantitative evaluation using a questionnaire and clinical examination trying to present more accurate results using an objective evaluation method..$^{22}$ The clinical indexes of hygiene and

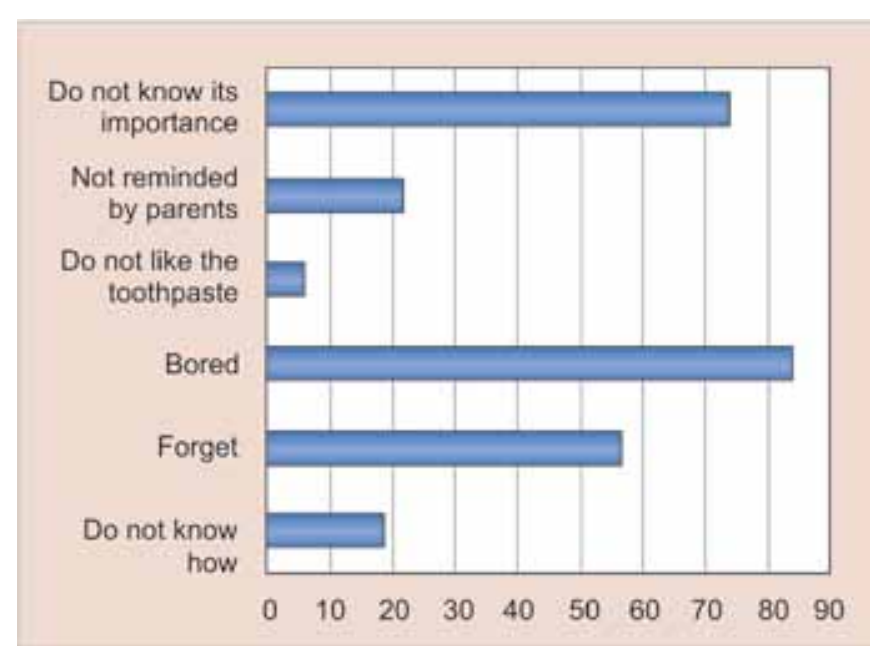

Graph 2: Histogram of children beliefs' regarding brushing avoidance of their peers 


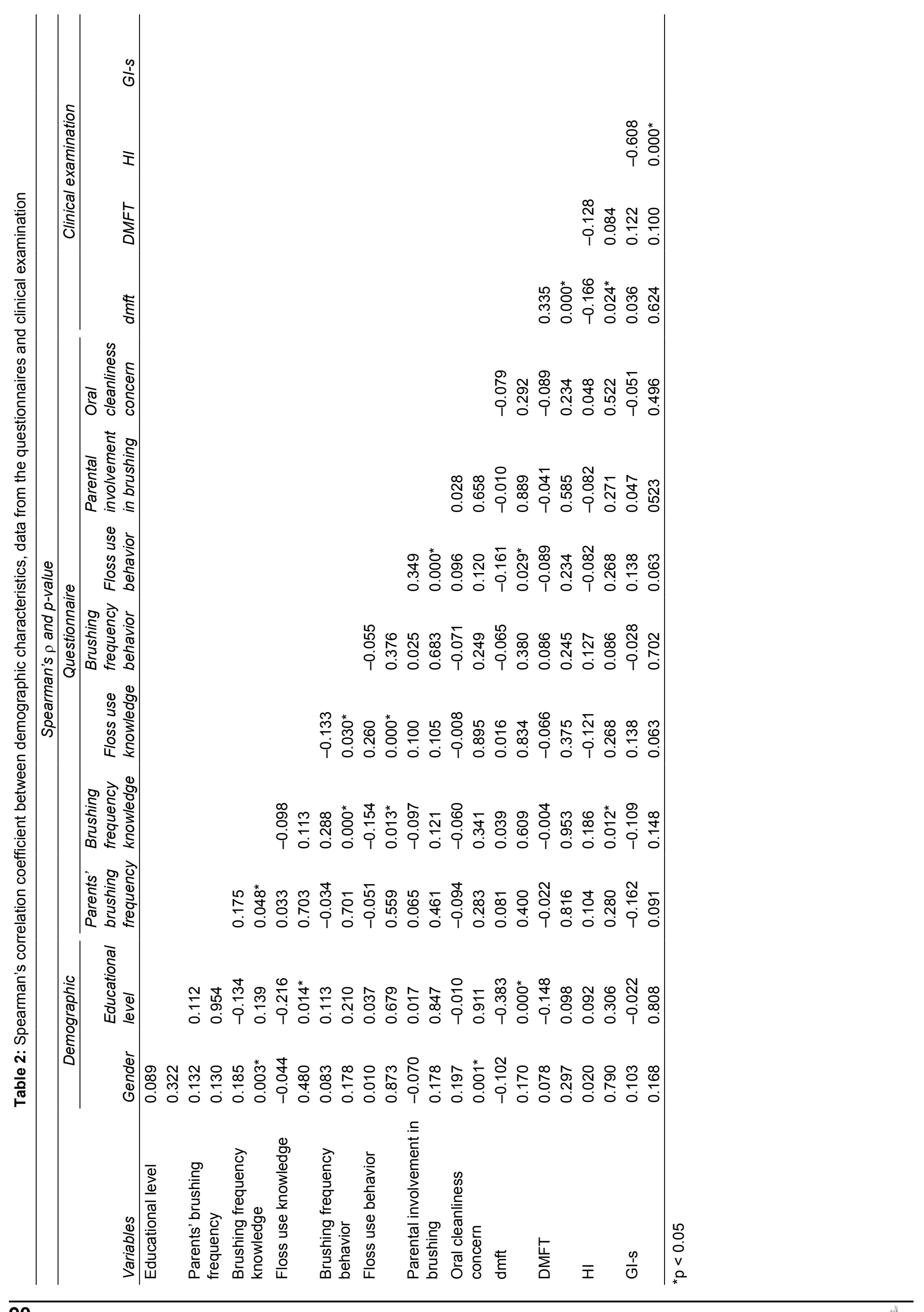


Table 3: Facilitators and barriers for oral hygiene in 10 years old children

\begin{tabular}{ll}
\hline Facilitators & Barriers \\
\hline $\begin{array}{l}\text { Enhancement of oral health } \\
\text { knowledge through oral health } \\
\text { education }\end{array}$ & $\begin{array}{l}\text { Lower socioeconomic level is } \\
\text { related to poorer oral health }\end{array}$ \\
$\begin{array}{l}\text { Improve parental oral health } \\
\text { behavior through oral health }\end{array}$ & $\begin{array}{l}\text { Common reason for brushing } \\
\text { avoidance is boredom }\end{array}$ \\
$\begin{array}{l}\text { education } \\
\text { The use of appealing }\end{array}$ & $\begin{array}{l}\text { Literate the schoolchildren } \\
\text { toothpaste as a motive for oral } \\
\text { regarding the importance of } \\
\text { health behavior improvement } \\
\text { Children concerns about oral } \\
\text { cleanliness as a motive to } \\
\text { enhance their oral hygiene }\end{array}$ \\
\hline
\end{tabular}

gingivitis were chosen because they are simple, easy and have high reliability, since they are based on the presence or absence of bleeding and dental plaque despite examiner's estimation. ${ }^{17}$ Dental caries were assessed using the commonly used BASCD criteria and the DMFT index so as to compare the results with previous studies and epidemiological data.

Data from this study show that although schoolchildren knew the appropriate brushing frequency of twice a day ${ }^{1-3}$ still 30\% does not practice it, showing that knowledge is not adequate to adopt a brushing habit. ${ }^{13,23,24}$ Knowledge of brushing frequency was correlated with actual reported frequency of brushing and oral hygiene clinical findings, showing that children that have the knowledge tend to brush more frequently. Thus, as has been reported in the past. Daily tooth brushing frequency of children found presently was similar to the one reported in other studies. ${ }^{3-5,11,15,25}$ Parental brushing frequency as expected was correlated with knowledge of brushing frequency of children. 9,10,12,26,27 The above shows that children follow the parental behavior and thus parents should also be the target in the oral health education programs addressed to children. ${ }^{16,28}$ However, peers influence has also been reported in young schoolchildren. ${ }^{14}$

Toothpaste is much enjoyed and is widely used by schoolchildren, suggesting that making the toothpaste more appealing can be a valuable tool in caries reduction and in this age population. ${ }^{29,30}$ Thus, toothpaste industry could focus more in offering appealing flavors and attractive designs with adequate fluoride in schoolchildren's toothpastes. Also, oral health promotion programs should direct their efforts on free distribution of toothpastes to children.

Many children knew the use of the dental floss and this was positively correlated with parental educational level. This finding maybe attributed to the rarer use of dental floss by parents with lower educational level so this behavior was not known from children., ${ }^{1,5,10,11,15}$
Practicing flossing by children was positively correlated with supervised brushing by their parents showing that parents with oral hygiene literacy understand better the importance of their children's oral hygiene. However, knowledge is not sufficient to persuade their children to floss their teeth since only $37 \%$ of children reported the use of floss for their oral hygiene. Limited use of floss has been reported in the past., $3,15,31$ Primary schoolchildren's attitude regarding oral hygiene has been limitedly reported in dental literature. In the current study it is apparent that mouth cleanliness and personal appearance is of high importance. ${ }^{1,14,16,23}$ This finding was more evident for girls, possibly because girls of that age are more mature than boys, entering their adolescence when personal appearance is quite important. Besides, many studies have reported that girls tend to have better oral hygiene. $3,5,7,9,11,15,25$

Barriers found for the application of oral hygiene in schoolchildren were boredom, ignorance of oral hygiene's importance and forgetfulness. Forgetfulness and lack of time have been previously reported as oral hygiene barriers in older children. ${ }^{13}$ These findings can help oral health education programs to set realistic goals. It is well known that oral hygiene can be improved with oral health education. ${ }^{32-34}$ Especially if it is implemented in regular intervals to sustain this knowledge $\mathrm{e}^{32-36}$ and possibly including more powerful scientific evidence regarding oral hygiene negligence outcomes. ${ }^{28}$ More importantly dental providers should focus on methods to remind and motivate children to oral hygiene. ${ }^{28}$ Oral hygiene campaigns using schoolchildren's favorite athletes, movie stars or singers may help improve their oral health. Stickers, posters, TV commercials and phone apps are some other means to be included. ${ }^{1,23}$ Clocks and timers that remind children to brush their teeth could also be useful, $^{16}$ as well as keeping the toothbrush next to the child's bed to remind them to brush and to motivate them to do it without making the effort to visit the bathroom. ${ }^{28}$

Results of this study could be used in the future for the design of oral health education programs for this specific age group. Also, it would be interesting to develop similar studies in other cultures do define the facilitators and barriers in other cultures. Moreover, since barriers have been defined, governments, oral health companies and dental professional should focus on taking measures to overcome these barriers.

Concerns about how clean were their teeth, oral health literacy of children's and parents' and their choice of toothpaste were found as facilitators for oral hygiene, whereas, children's boredom, low oral health literacy, forgetfulness and low socioeconomic level were found as barriers. 


\section{REFERENCES}

1. Choo A, Delac DM, Messer LB. Oral hygiene measures and promotion: review and considerations. Aust Dent J 2001;46(3): 166-173.

2. Loe H. Oral hygiene in the prevention of caries and periodontal disease. Int Dent J 2000;50(3):129-139.

3. Kuusela S, Honkala E, Kannas L, Tynjala J, Wold B. Oral hygiene habits of 11-year-old schoolchildren in 22 European countries and Canada in 1993/1994. J Dent Res 1997;76(9): 1602-1609.

4. Zaborskis A, Milciuviene S, Narbutaite J, Bendoraitiene E, Kavaliauskiene A. Caries experience and oral health behaviour among 11 to 13-year-old: an ecological study of data from 27 European countries, Israel, Canada and USA. Community Dent Health 2010;27(2):102-108.

5. Maes L, Vereecken C, Vanobbergen J, Honkala S. Tooth brushing and social characteristics of families in 32 countries. Int Dent J 2006;56(3):159-167.

6. Vadiakas G, Oulis CJ, Tsinidou K, Mamai-Homata E, Polychronopoulou A. Oral hygiene and periodontal status of 12 and 15-year-old Greek adolescents. A national pathfinder survey. Eur Arch Paediatr Dent 2012;13(1):11-20.

7. Macgregor ID, Balding JW, Regis D. Motivation for dental hygiene in adolescents. Int J Paediatr Dent 1997;7(4):235-241.

8. Levin KA, Currie C. Adolescent toothbrushing and the home environment: sociodemographic factors, family relationships and mealtime routines and disorganisation. Community Dent Oral Epidemiol 2010;38(1):10-18.

9. Vallejos-Sanchez AA, Medina-Solis CE, Maupome G, Casanova-Rosado JF, Minaya-Sanchez M, Villalobos-Rodelo JJ, et al. Sociobehavioral factors influencing toothbrushing frequency among schoolchildren. J Am Dent Assoc 2008;139(6):743-749.

10. Casanova-Rosado JF, Vallejos-Sanchez AA, MinayaSanchez M, Medina-Solis CE, De La Rosa-Santillana R, Marquez-Corona Mde L, et al. Frequency of tooth brushing and associated factors in Mexican schoolchildren 6 to 9 years of age. West Indian Med J 2013;62(1):68-72.

11. Villalobos-Rodelo JJ, Medina-Solis CE, Maupome G, VallejosSanchez AA., Lau-Rojo L, de Leon-Viedas MV. Socioeconomic and sociodemographic variables associated with oral hygiene status in Mexican schoolchildren aged 6 to 12 years. J Periodontol 2007;78(5):816-822.

12. Kumar S, Panwar J, Vyas A, Sharma J, Goutham B, Duraiswamy $\mathrm{P}$, et al. Tooth cleaning frequency in relation to sociodemographic variables and personal hygiene measures among school children of Udaipur district, India. Int J Dent Hyg 2011;9(1):3-8.

13. Kasila K, Poskiparta M, Kettunen T, Pietila I. Oral health counselling in changing schoolchildren's oral hygiene habits: a qualitative study. Community Dent Oral Epidemiol 2006; 34(6):419-428.

14. Koerber A, Graumlich S, Punwani IC, Berbaum ML, Burns JL, Levy SR, et al. Covariates of tooth-brushing frequency in low-income African Americans from grades 5 to 8. Pediatr Dent 2006;28(6):524-530.

15. Honkala S, Honkala E, Al-Sahli N. Do life- or school-satisfaction and self-esteem indicators explain the oral hygiene habits of schoolchildren? Community Dent Oral Epidemiol 2007;35(5):337-347.
16. Gill P, Stewart K, Chetcuti D, Chestnutt IG. Children's understanding of and motivations for toothbrushing: a qualitative study. Int J Dent Hyg 2011;9(1):79-86.

17. Lindhe J, Socransky SS, Nyman S, Haffajee A, Westfelt E. 'Critical probing depths' in periodontal therapy. J Clin Periodontol 1982;9(4):323-336.

18. Pitts NB, Evans DJ, Pine CM. British association for the study of community dentistry (BASCD) diagnostic criteria for caries prevalence surveys-1996/97. Comm Dent Health 1997;14 (Suppl) 1:6-9.

19. Angelopoulou MV, Oulis CJ, Kavvadia K. School based oral health education program using Experiential Learning or Traditional Lecturing in adolescents: a clinical trial. Int Dent J 2014;64(5):278-284.

20. Gill P, Stewart K, Treasure E, Chadwick B. Conducting qualitative interviews with school children in dental research. $\mathrm{Br}$ Dent J 2008;204(7):371-374.

21. Astrom AN, Jakobsen R. Stability of dental health behavior: a 3-year prospective cohort study of 15-, 16- and 18-year-old Norwegian adolescents. Community Dent Oral Epidemiol 1998;26(2):129-138.

22. Johnston M, Dixon D, Hart J, Glidewell L, Schroder C, Pollard B. Discriminant content validity: a quantitative methodology for assessing content of theory-based measures, with illustrative applications. Br J Health Psychol 2014.

23. Tolvanen M, Lahti S, Hausen H. Changes in toothbrushing frequency in relation to changes in oral health-related knowledge and attitudes among children-a longitudinal study. Eur J Oral Sci 2010;118(3):284-289.

24. Kay EJ, Locker D. Is dental health education effective? A systematic review of current evidence. Community Dent Oral Epidemiol 1996;24(4):231-235.

25. Addy M, Dummer PM, Hunter ML, Kingdon A, Shaw WC. The effect of toothbrushing frequency, toothbrushing hand, sex and social class on the incidence of plaque, gingivitis and pocketing in adolescents: a longitudinal cohort study. Community Dent Health 1990;7(3):237-247.

26. Saied-Moallemi Z, Virtanen JI, Ghofranipour F, Murtomaa H. Influence of mothers' oral health knowledge and attitudes on their children's dental health. Eur Arch Paediatr Dent 2008;9(2):79-83.

27. Rajab LD, Petersen PE, Bakaeen G, Hamdan MA. Oral health behaviour of schoolchildren and parents in Jordan. Int J Paediatr Dent 2002;12(3):168-176.

28. Huebner CE, Riedy CA. Behavioral determinants of brushing young children's teeth: implications for anticipatory guidance. Pediatr Dent 2010;32(1):48-55.

29. Marthaler TM. Changes in dental caries 1953-2003. Caries Res 2004;38(3):173-181.

30. Bratthall D, Hansel-Petersson G, Sundberg H. Reasons for the caries decline: what do the experts believe? Eur J Oral Sci 1996;104(4 (Pt 2)):416-422.

31. Macgregor ID, Balding JW, Regis D. Flossing behaviour in English adolescents. J Clin Periodontol 1998;25(4): 291-296.

32. Biesbrock AR, Walters PA, Bartizek RD. Short-term impact of a national dental education program on children's oral health and knowledge. J Clin Dent 2004;15(4):93-97. 
33. Worthington HV, Hill KB, Mooney J, Hamilton FA, Blinkhorn AS. A cluster randomized controlled trial of a dental health education program for 10-year-old children. J Public Health Dent 2001;61(1):22-27.

34. Hartono SW, Lambri SE, van Palenstein Helderman WH. Effectiveness of primary school-based oral health education in West Java, Indonesia. Int Dent J 2002;52(3):137-143.
35. Ekstrand KR, Kuzmina IN, Kuzmina E, Christiansen ME. Two and a half-year outcome of caries-preventive programs offered to groups of children in the Solntsevsky district of Moscow. Caries Res 2000;34(1):8-19.

36. Allison PJ, Schwartz S. Interproximal contact points and proximal caries in posterior primary teeth. Pediatr Dent 2003;25(4):334-340. 